no better off. Apart from this, the report suggests that some Australian practices might be adopted, in particular the one which requires all "incidents" which might have led to accidents to be reported. More than 5,000 such incidents are reported each year, and the information derived from them is undoubtedly very useful. But pilot error is still the most substantial cause of accidents; better training and better flight deck management are suggested as ways of reducing this.

\section{Television from the East}

LATER this year, work is to start on re-equipping the telecommunications station at Goonhilly so that it can handle telephone and television traffic between Britain and Australia, India, Pakistan, Japan and other countries in the Far East. The aerial at Goonhilly is at present dealing with communications across the Atlantic with the Early Bird satellite, but a second aerial is under construction and will take over the Atlantic route, relaying signals via the first Intelsat III satellite, later this year. The first aerial will then be free for improvements to be carried out, so that it can match the sophistication of the new generation of communications satellites and the increased number of communications channels they can carry.

\section{Sorry, for copyright reasons some images on this page may not be available online}

\begin{abstract}
New aerial under construction at Goonhilly. (Crown copyright, courtesy of HM Postmaster General.)
\end{abstract}

The Post Office expects the modifications to be completed in the first half of 1969 , when Goonhilly will have facilities for 264 two-way telephone channels between Britain and 12 different stations in the Far East, relayed through another Intelsat III satellite over the Indian Ocean. The system will also be able to carry 625 line colour television programmes. GEC-AEI (Electronics) Ltd have been awarded a $\mathfrak{1 4 0 0 , 0 0 0}$ contract by the Post Office to carry out the work.

\section{More Nuclear Power}

The Central Electricity Generating Board has asked the Ministry of Power for permission to build another nuclear power station at Sizewell in Suffolk. This means that there are now five stations awaiting decisions from the Ministry-Seaton Carew in County Durham, Heysham in the North West, Sizewell $B$ (all nuclear stations); the Isle of Grain oil fired station, and a coal fired station at West Burton. The ministry is continuing to drag its heels over the Seaton Carew decision, and the CEGB will doubtless be hoping that a decision can be reached on Sizewell very much more quickly than this. The station, powered by four advanced gas cooled reactors, would be a very big one, generating 2,500 MW of electricity, and would be on the same site as the existing Sizewell $A$ station, a nuclear station of the Magnox type, which generates $580 \mathrm{MW}$. For this reason, it should be possible to estimate the cost of the new station with considerable accuracy; the geology of the site is known, access roads are built, and the conditions of water supply are known. The policy of building new stations on the same site as the old ones also means that amenity interests are less of a problem-once the first station is built, local residents are less likely to complain about the building of a new one.

This time the CEGB is looking for a quick decisionit wants the new station to come into operation by 1974. Nuclear stations in Britain take a long time to build, so that construction should begin by the end of 1969. Requests for tenders should go out at the end of this year, which gives the ministry six months to make up its mind-about the time it usually takes. This leisurely rate of progress has its critics, although delays in the initial planning stage are much less costly than those occurring during the building of the station. (The worst thing of all is when the station keeps breaking down after commissioning; this is rare in Britain, but did happen at Trawsfynydd in Wales with a Magnox station.) For a station of this

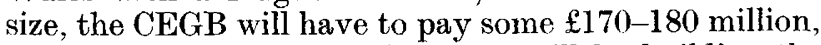
but it is still not at all clear who will be building the station. Discussions about the reorganization of the nuclear power industry are still in progress, with the Industrial Reorganization Corporation called in as court wizards to try to sort out the mess created by the joint efforts of the CEGB, the Atomic Energy Authority, the Ministries of Power and Technology, and the House of Commons Select Committee on Science and Technology.

\section{Maps, Missals and Watermarks}

A TECHNIQUe for dating documents by beta-radiography of their watermarks has been developed by $\mathrm{Dr}$ Allan Stevenson of the British Museum. The technique has already been used on the Vinland map, the Constance Missal and undated Caxton manuscripts.

Early papermakers used watermarks both as trademarks and to signify different grades of paper. The wire moulds that formed the watermark lasted for not more than two years and tended to deteriorate in a recognizable manner. Documents can thus be dated with some precision by comparing their watermarks with those in documents of known date.

Watermarks in the pages of old books and documents, however, tend to be faint or invisible, and with the naked eye their details cannot be discriminated exactly enough for dating purposes. Dr Stevenson has found that very precise impressions can be gained by betaradiography. He places a 'Perspex' sheet embedded 


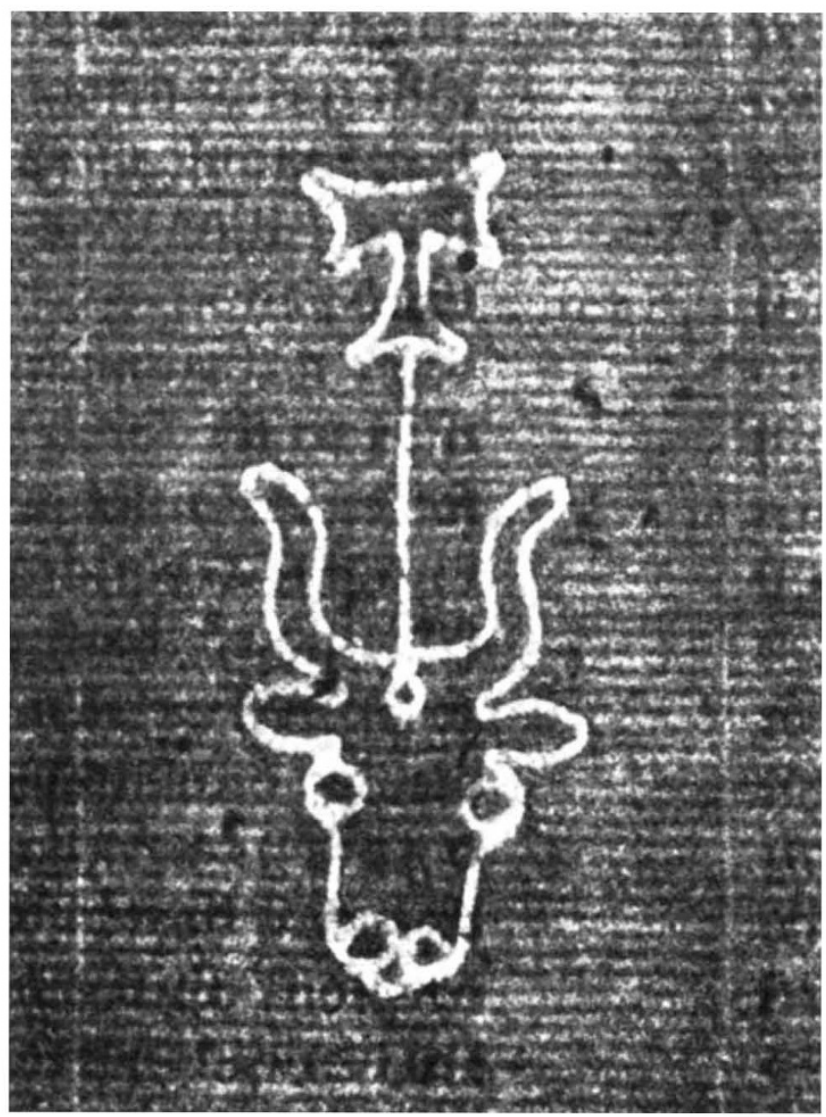

Watermark from Caxton's Golden Legend, about I484. Radiograph by Dr Allan Stevenson.

with carbon-14 on one side of a page and a sensitive film on the other. The radiation penetrates the thinner areas of the paper that constitute the watermark and leaves a precisely defined contact print on the film. The print is usually unobscured by printed matter unless an ink containing iron has been used. Pages can be examined without being removed from their bindings and they are not damaged by the radiation. The 6 in. $\times 4$ in. 'Perspex' sheets are supplied by the Radiochemical Centre, Amersham, at a price of $£ 200$ each; the half-life of a sheet, however, is of course 5,760 years.

Dr Stevenson has dated the Vinland map by this technique. The map caused some excitement at its recent publication because it shows the coastlines of Greenland and North America, but was apparently drawn before Columbus's voyage of 1492 and presumably on the experience of voyages made by Norsemen. Its authenticity has been questioned, in particular by Columbus's compatriots. The map itself is drawn on vellum, which bears no watermarks, but Dr Stevenson finds that the watermarks in the accompanying manuscript establish that the paper was made in about 1450 in the Piedmontese town of Caselle.

The Constance Missal was purchased by the Pierpont Morgan Library, New York, in 1954 on the assumption that it was the earliest extant printed book in Europe. Dr Stevenson showed that its watermarks dated it to 1473 and that it had not been printed by Gutenberg, as previously supposed.

Radiographs are also helpful in studying Caxton's books, about half of which are undated. Watermark variations in the bull's head paper which Caxton used in his first two books, the Recuyell of the Histories of Troie and The Game and Play of Chess allow both these works to be dated to 1474 .

\section{Physics at Exeter}

THE physics building at the University of Exeter was inaugurated this week with a general feeling of relief. As the third and final stage of a building programme originally planned to be finished by 1963 , the building was overdue before building work even began in 1964, but the department is glad to have its new premises and is not mentioning the delays. The chemistry building was the first stage of the plan; this was followed by a joint lecture room block which has been in use since December 1966, and now the physics building, parts of which have been in use for 18 months, is complete. All three stages have characteristic horizontal bands of brickwork with long horizontal windows for the large rooms--teaching laboratories and workshops, and close-centred vertical fins where the rooms are small and of varying sizes. The physics building consists of a long two-storey block containing workshops and laboratories for first and second year undergraduate teaching and main research, and a ninestorey tower (see photograph) containing staff offices, third year teaching laboratories and the department library. The radioactive laboratories are housed underground below the tower.

About $£ 900,000$ has been spent so far on the physics building, with about $£ 250,000$ being used for equipment. With about 76,100 square feet of floor space

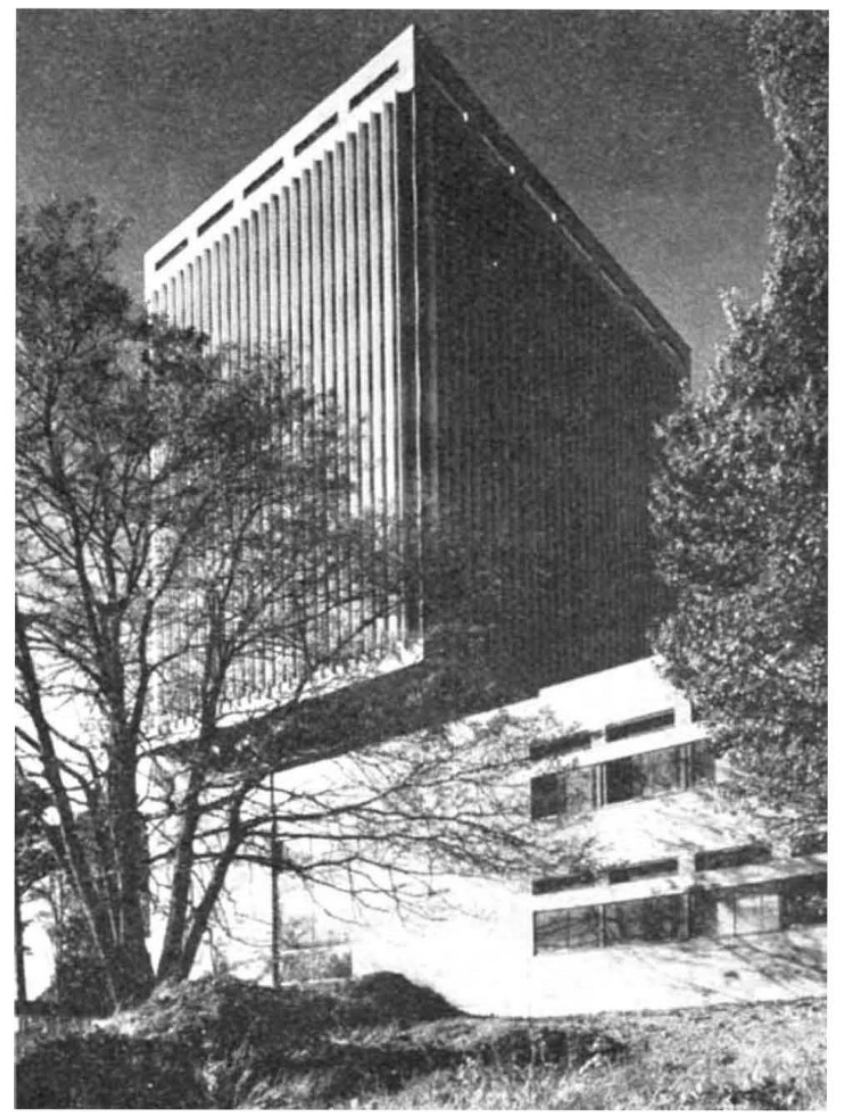

The new physics building at Exeter. (Photo: Henk Snoek.) 